\title{
Electrochemical Behavior of Dissimilar Carbon-Stainless Steel RSW Joints
}

\author{
Results showed formation of martensite in the fusion zone \\ produced elevated hardness values and was detrimental to \\ corrosion resistance of the material in acid media
}

BY D. F. SILVA AND P. P. BRITO

\begin{abstract}
In the present investigation, the electrochemical behavior of dissimilar welds between austenitic stainless steel and low-carbon steel obtained by resistance spot welding was investigated. The results obtained showed the formation of martensite in the fusion zone produced elevated hardness values $(\sim 480 \mathrm{HV})$ and was detrimental to the corrosion resistance of the material in acid media $(0.5 \mathrm{M}$ $\mathrm{H}_{2} \mathrm{SO}_{4}$ containing naturally dissolved $\mathrm{O}_{2}$ ). The susceptibility of the welded joints to hydrogen embrittlement was studied by applying cathodic charging in acid solution, which led to a $42 \pm 5 \%$ reduction in maximum elongation compared to noncharged specimens.
\end{abstract}

\section{KEYWORDS}

- Dissimilar Welding • Resistance Spot Welding (RSW)

- Electrochemical Impedance Spectroscopy

- Potentiodynamic Polarization

- Hydrogen Embrittlement

\section{Introduction}

The resistance spot welding (RSW) process is widely used in industry today due to its elevated productivity, ease of automation, low cost, and absence of potentially hazardous fumes or gases, among other reasons. In a typical RSW joint, a localized union is produced between overlapped sheets by the passage of an electrical current, which causes heat generation by Joule effect. The electrodes employed also serve the purpose of applying force to the joint to assist the formation of a metallurgical bond between the materials. The RSW process is applied prominently in the automotive industry, and it is estimated that between 2000 and 5000 spot welds can be found in a modern vehicle (Ref. 1).
The union of dissimilar materials by welding can be a complex technical issue because of differences in chemical composition and microstructures, as well as mechanical or physical properties. For instance, differences in the thermal expansion coefficient may contribute to the formation of residual stresses in dissimilar joints between ferritic and austenitic steels (Ref. 2), and brittle intermetallic compounds may be found in dissimilar welds of aluminum and steel (Ref. 3). In this context, the RSW process is interesting because it provides a small-volume fusion zone in comparison to arc welding processes, which may contribute to minimizing material incompatibilities. In fact, it is worth noticing the number of studies performed in recent years with the objective of investigating the union of structural carbon steels and stainless steels by RSW (Refs. 4-8), providing a cost-effective alternative to the use of bulk corrosionresistant materials and the means to integrate stainless steels with conventional structural steels in new designs.

Most investigations carried out to date concerning dissimilar RSW between carbon and stainless steels have focused on the mechanical behavior and microstructure formation of the welded joints (Refs. 4-6, 9-11) with relatively less attention directed toward the actual electrochemical behavior (Refs. 8, 12). In dissimilar RSW between carbon and stainless steels, the fusion zone (FZ) microstructure is reported to be predominantly martensitic, due to base metal dilution and elevated cooling rates (Ref. 5), in contrast with the FZ present in similar austenitic stainless steel RSW, reported to consist of dendritic austenite with $\delta$-ferrite in interdendritic regions (Refs. 13-15). These modifications can be detrimental to the corrosion resistance of the joints because of the reduction in $\mathrm{Cr}$ and Ni levels in the FZ and may also impair mechanical integrity in hydrogen-containing media because the presence of martensite increases susceptibility to hydrogen embrittlement (Refs. 12, 16-18). As such, in the present experimental work, dissimilar RSW joints between austenitic stainless steel and low-carbon 


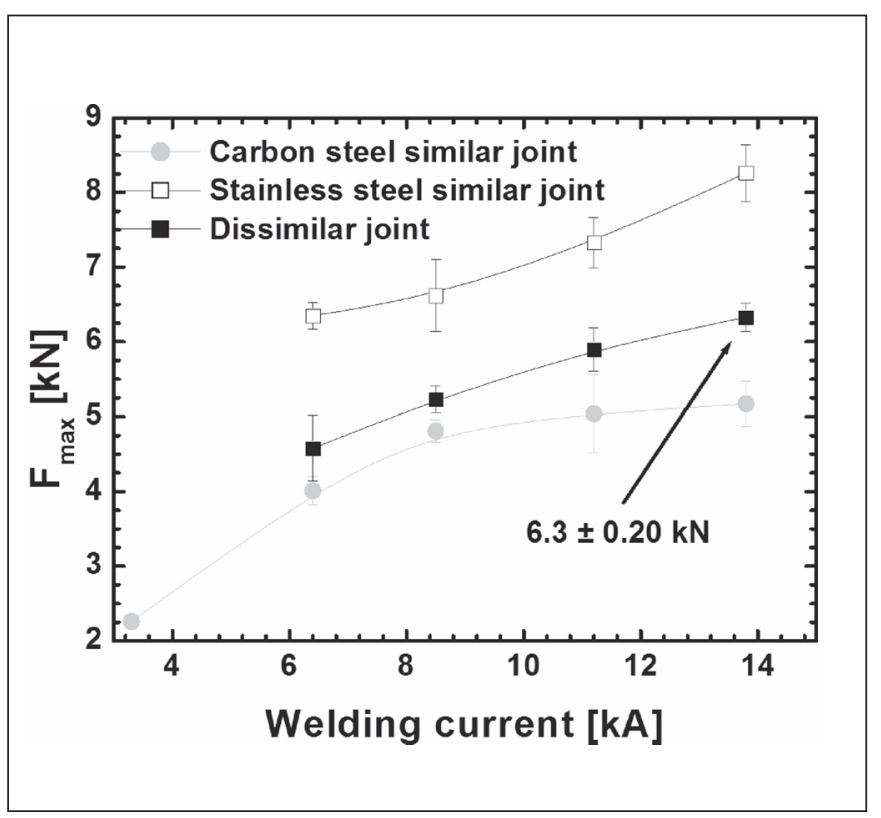

Fig. 1-Peak load $\left(F_{\max }\right)$ of similar and dissimilar low-carbon steel and austenitic stainless steel RSW joints.

steel in acid media were investigated, with the objective of exploring the relation between the microstructure in the FZ with the electrochemical properties of the weld.

\section{Experimental Procedure}

\section{Materials}

The materials used in the welding experiments were 100 $\times 25 \times 1 \mathrm{~mm}$ sheets of austenitic stainless steel (nominally AISI 316L) and low-carbon steel (nominally AISI 1008), with the chemical composition presented in Table 1 (the $\mathrm{Cr}$ - and $\mathrm{Ni}$-equivalent values of each steel are also presented). The registered composition matches the requirements for the carbon steel standard specification, but in the case of the austenitic stainless steel, the contents of $\mathrm{Ni}$ and Mo were found to be smaller than required. The joints were positioned such that a $25 \times 25 \mathrm{~mm}^{2}$ overlap was formed in each case, at the center of which the electrodes were positioned for RSW.

The welding operations were carried out using laboratory RSW equipment with a maximum power output of $15 \mathrm{kVA}$, fixed welding time of $1 \mathrm{~s}$, and welding currents of 3.3, 6.4, 8.5, 11.2, and 13.8 kA. Similar (of both steels) and dissimilar welds were produced. The average surface roughness $\left(R_{a}\right)$ of the stainless and carbon steel sheets were, respectively, $0.3 \pm$ $0.1 \mu \mathrm{m}$ and $1.3 \pm 0.2 \mu \mathrm{m}$, and the materials were ground in 400 -grit $\mathrm{SiC}$ paper before welding operations to remove surface contaminants. Truncated-cone $\mathrm{Cu}$ electrodes with a tip diameter of $8.3 \mathrm{~mm}$ and a tip angle of $27 \mathrm{deg}$ were used for performing the welds. The electrodes were produced from C11000 electrolytic $\mathrm{Cu}$ alloy and were not seasoned before the experimental procedures. Prior to each welding experiment, the geometry of the electrode tip was verified and, when necessary, machined to ensure the same geometry for all test conditions.

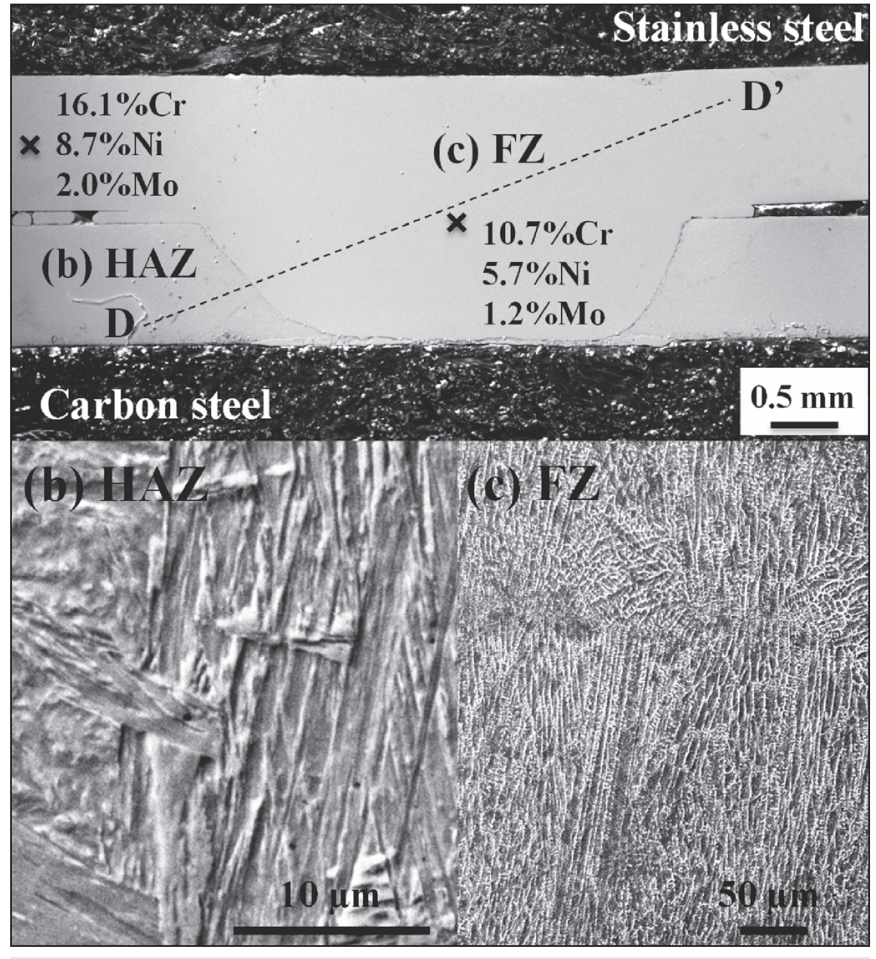

Fig. 2 - Cross-section overview of a dissimilar joint between low-carbon steel and austenitic stainless steel obtained by RSW with 13.8-KA welding current.

\section{Mechanical Properties}

After joining, the mechanical strength of the welded specimens was evaluated by employing tensile-shear tests. A total of three tests were performed for each value of welding current. The results were obtained in the form of force $(\mathrm{F})$ vs. displacement $(\Delta \mathrm{l})$ curves, from which the peak load was obtained. The dissimilar joints that exhibited best performance (analyzed in terms of failure mode and peak load) were then selected for further analyses. The susceptibility to hydrogen embrittlement of the welded joints was also analyzed by tensile-shear tests by comparing results obtained before and after cathodic charging in a $0.5 \mathrm{M} \mathrm{H}_{2} \mathrm{SO}_{4}$ solution containing $0.25 \mathrm{~g} / \mathrm{L}$ $\mathrm{NaAsO}_{2}$ at $100 \mathrm{~mA} / \mathrm{cm}^{2}$ for $24 \mathrm{~h}$ (Ref. 19). A hydrogen embrittlement index was determined based on the relative difference in maximum displacement between the charged and pristine samples (Ref. 20). All tensile-shear tests were performed using a $5-\mathrm{mm} / \mathrm{min}$ cross-head displacement speed.

Local hardness variations within the dissimilar weld were assessed by performing Vickers microhardness indentations along the cross section of selected joints. The tests were performed using a Shimadzu HMV tester with a 245.2-mN load (HV 0.025), 20-s load time, and 0.08-mm distance between indentations across a line that starts at the carbon steel base material toward the stainless steel base material through the FZ (see Fig. 2).

\section{Weld Nugget Characterization}

The cross-section morphology of the dissimilar weld produced with 13.8-kA welding current was analyzed by scan- 


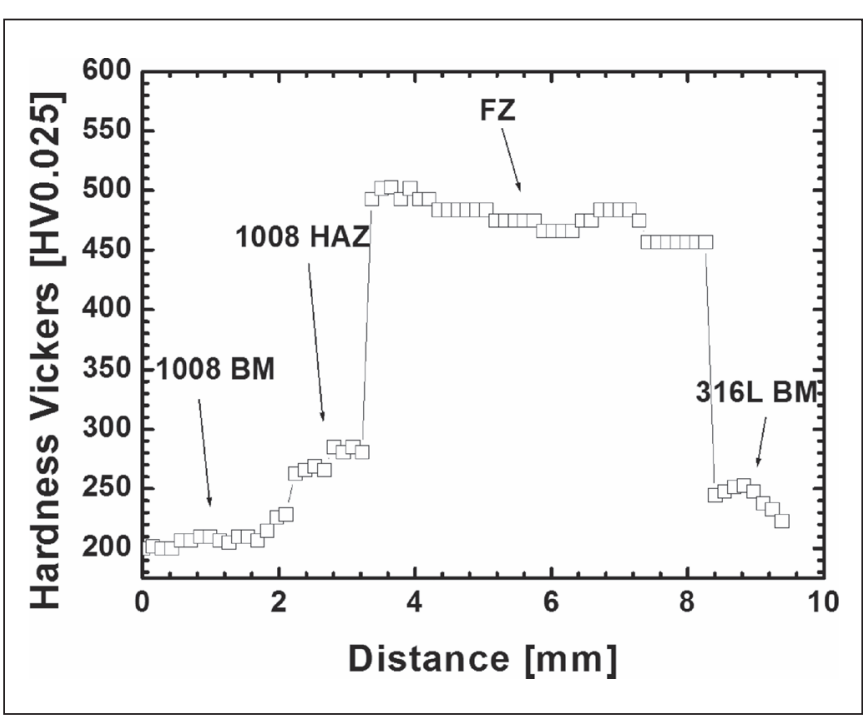

Fig. 3 - Vickers microhardness profile along line DD' (Fig. 2).

ning electron microscopy (SEM). The preparation procedure involved grinding and polishing down to a $1-\mu \mathrm{m}$ finish in an $\mathrm{Al}_{2} \mathrm{O}_{3}$ suspension, and observations were made in a JEOL IT300 microscope equipped with an Oxford/X-Max ${ }^{\mathrm{N}}$ energy dispersive $\mathrm{x}$-ray spectroscopy (EDX) detector for semiquantitative chemical composition analysis.

\section{Electrochemical Corrosion Behavior}

The electrochemical corrosion behavior of the dissimilar welded joints was analyzed and compared with the stainless steel base material. The tests were performed by exposing the top surface of the spot weld (from the stainless steel side) to a $0.5 \mathrm{M} \mathrm{H}_{2} \mathrm{SO}_{4}$ aqueous solution containing naturally dissolved $\mathrm{O}_{2}$ at $25^{\circ} \mathrm{C}$. Before corrosion testing, the surface of the spot welds was ground in 1000-grit $\mathrm{SiC}$ paper to produce a homogenous surface finish among the tested groups, then rinsed in water, followed by ethanol, and dried. A threeelectrode setup was employed, with a Pt counterelectrode and $\mathrm{Ag} / \mathrm{AgCl}$ in saturated $\mathrm{KCl}$ as reference electrode. A 400$\mathrm{mL}$ volume horizontal cell prepared for flat specimens with a 5-mm-diameter orifice for exposing the samples to the electrolyte was used. The diameter of the electrochemical cell was chosen because it was smaller than the spot weld diameter (approximately $8 \mathrm{~mm}$ ). Special care was taken during preparation of the corrosion tests to ensure the spot weld was centered relative to the orifice of the electrochemical cell, so the examined area consisted only of the welded region and did not incorporate the base material. Because of

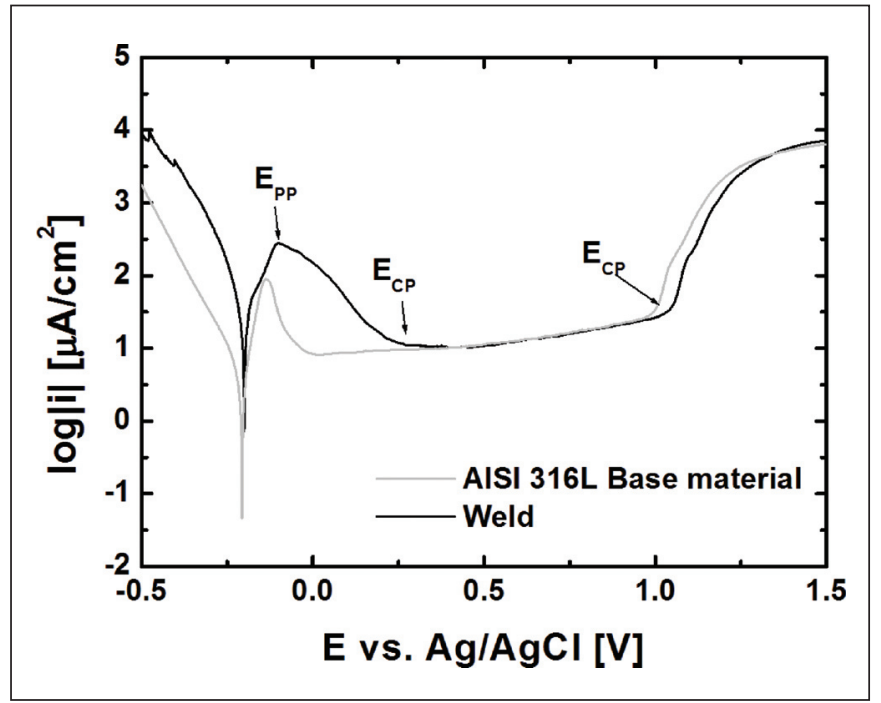

Fig. 4 - Potentiodynamic polarization curves obtained for the austenitic stainless steel BM and for the FZ of the dissimilar welded joint in $0.5 \mathrm{M} \mathrm{H}_{2} \mathrm{SO}_{4}$ containing naturally dissolved $\mathrm{O}_{2}\left(\mathrm{E}_{\mathrm{pp}}\right.$ - potential for primary passivation; $E_{c p}$ - potential for complete passivation; $E_{t p}-$ transpassive potential).

the relatively small analyzed surface, a total of five measurements were performed on different welded and reference samples.

During initial stabilization, the open circuit potential (OCP) was monitored for $1.5 \mathrm{~h}$ before analysis by electrochemical impedance spectroscopy (EIS) and potentiodynamic polarization (PP). The EIS analysis was carried out at the stabilized OCP by applying a $10-\mathrm{mV}$ sinusoidal excitation signal with frequencies varying from 100,000 to $0.01 \mathrm{~Hz}$, whereas the PP scans were performed at a $0.2-\mathrm{mV} / \mathrm{s}$ rate in $1-\mathrm{mV}$ steps from -0.5 to $1.5 \mathrm{~V}$. The corrosion current density $\left(\mathrm{i}_{\text {corr }}\right)$ was determined by extrapolation of the cathodic Tafel line to the corrosion potential $\left(\mathrm{E}_{\text {corr }}\right)$ because of different metal dissolution reactions, which yield nonlinear or poorly defined anodic Tafel lines (Ref. 21).

\section{Results and Discussion}

\section{Mechanical Properties}

The results of the tensile-shear tests are presented in Fig. 1 , in which peak load $\left(\mathrm{F}_{\max }\right)$ is plotted as a function of welding current for similar carbon steel, similar stainless steel, and dissimilar carbon-stainless steel welds. The maximum peak load value obtained for the dissimilar welds was $6.3 \pm$

Table 1-Chemical Composition (wt-\%) of the Materials Used in the Present Study, along with Cr-Equivalent $\left(\mathrm{Cr}_{\mathrm{eq}}\right)$ and $\mathrm{Ni}-\mathrm{Equivalent}\left(\mathrm{Ni}_{\mathrm{eq}}\right)$ Values

\begin{tabular}{lcccccccccc} 
& $\mathrm{C}$ & $\mathrm{Mn}$ & $\mathrm{P}$ & $\mathrm{S}$ & $\mathrm{Cr}$ & $\mathrm{Ni}$ & $\mathrm{Mo}$ & $\mathrm{Fe}$ & $\mathrm{Cr}_{\text {eq }}$ & $\mathrm{Ni}_{\text {eq }}$ \\
\hline Low-carbon steel & 0.07 & 0.38 & 0.01 & 0.01 & - & - & - & Base & 0.1 & 2.3 \\
Stainless steel & 0.02 & 1.27 & 0.03 & $<0.01$ & 17.11 & 9.45 & 1.71 & Base & 19.5 & 10.7 \\
& & & & & & & & & & \\
\hline
\end{tabular}




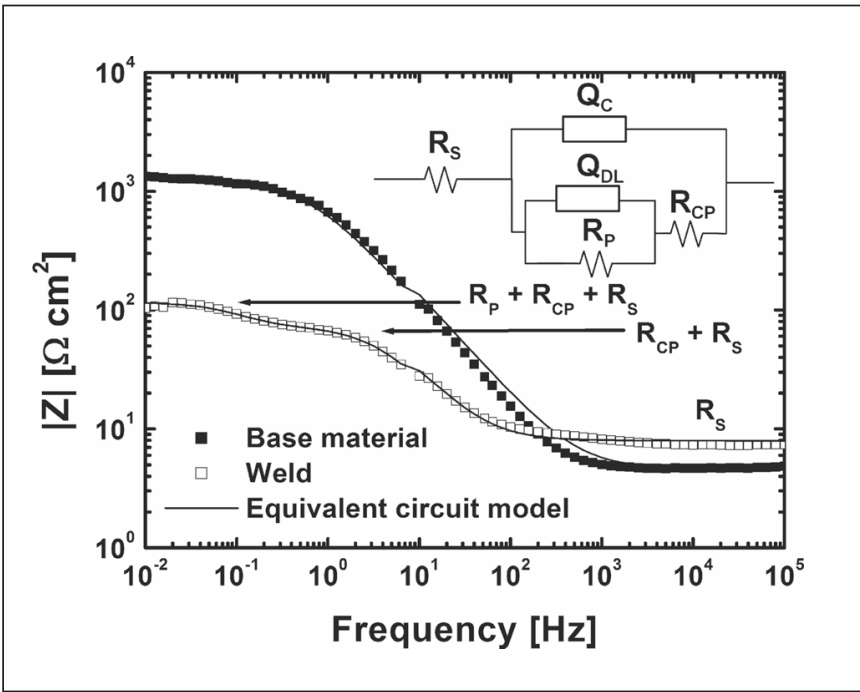

Fig. 5-Bode plots obtained by EIS at the stabilized OCP for the austenitic stainless steel base material and for the FZ of the dissimilar welded joint in $0.5 \mathrm{M} \mathrm{H}_{2} \mathrm{SO}_{4}$ containing naturally dissolved $\mathrm{O}_{2}$.

$0.2 \mathrm{kN}$ (standard deviation calculated from three measurements), as indicated. The lowest welding current setting (3.3 $\mathrm{kA}$ ) was found to be insufficient for effectively producing the similar and dissimilar welds, and these joints were consequently not submitted to tensile-shear testing. For all situations, the peak load was found to increase with welding current, probably in connection with the increase in weld nugget size (Refs. 4, 22). Two failure mechanisms were identified, which were interfacial fracture and nugget pullout, in agreement with previous investigations (Refs. 23-25). In some cases, after nugget pullout, the sheet was torn along the heat-affected zone (HAZ) of the AISI 1008 steel. The interfacial fracture mode was not observed in the similar stainless steel joints, but was noticed on the remaining conditions for welding currents of $6.4 \mathrm{kA}$ or less. For higher

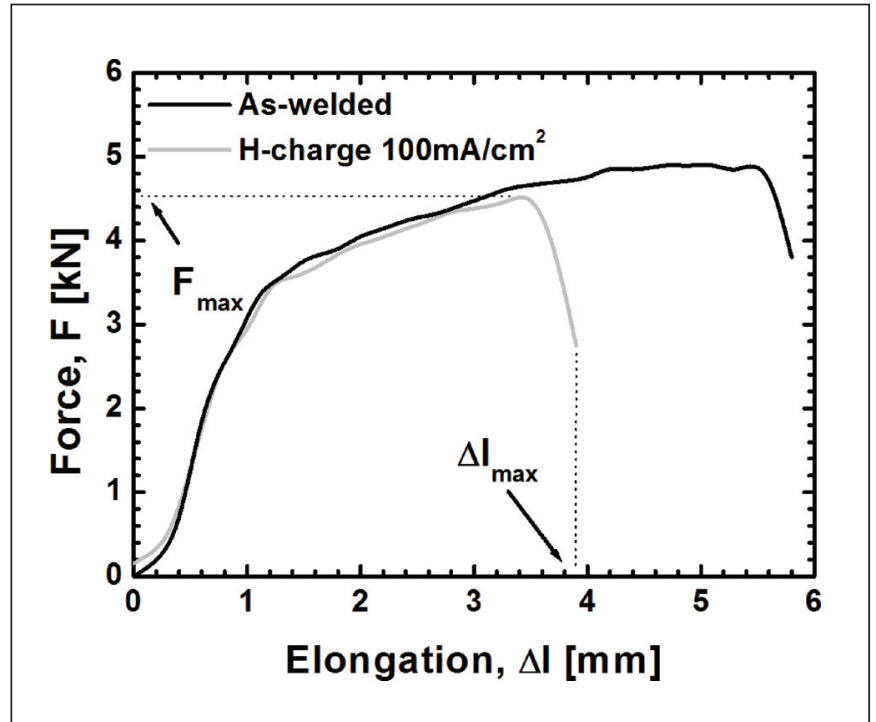

Fig. 6-Comparison of the force-displacement diagrams obtained from the dissimilar welded joints before and after hydrogen charging at $100 \mathrm{~mA} / \mathrm{cm}^{2}$.

welding current values, all joints failed by nugget pullout. The change in failure mode from interfacial to pullout is expected with the increase in peak load. For small weld nuggets, shear stresses reach a critical value before tensile stresses cause necking and above a certain weld nugget size pullout failure is expected (Ref. 5).

\section{Analysis of Weld Nugget}

The dissimilar welded joints that exhibited highest peak load in the tensile-shear tests were selected for further examination (13.8-kA welding current). A cross-sectional overview of the weld nugget is presented in Fig. 2A, which highlights EDS chemical composition analyses at the center of the FZ and stainless steel base material and the line DD'

Table 2 - Uniform Corrosion Parameters from Potentiodynamic Polarization Scans of Dissimilar RSW Joints (FZ) and Austenitic Stainless Steel Base Material (BM) in $0.5 \mathrm{M} \mathrm{H}_{2} \mathrm{SO}_{4}$ Containing Naturally Dissolved $\mathrm{O}_{2}$ at $25^{\circ} \mathrm{C}$

\begin{tabular}{cccc} 
& $E_{\text {corr }}(\mathrm{V} / \mathrm{Ag}-\mathrm{AgCl})$ & $\mathrm{i}_{\text {corr }}\left(\mu \mathrm{A} / \mathrm{cm}^{2}\right)$ & $\mathrm{b}_{\mathrm{c}}(\mathrm{V} / \mathrm{dec})$ \\
\hline BM & $-0.202 \pm 0.01$ & $10 \pm 10$ & $-0.115 \pm 0.01$ \\
FZ & $-0.224 \pm 0.02$ & $30 \pm 20$ & $-0.128 \pm 0.02$
\end{tabular}

$\mathrm{E}_{\text {corr }}-$ Corrosion potential; $\mathrm{i}_{\mathrm{corr}}-$ corrosion current density; $\mathrm{b}_{\mathrm{c}}$ - cathodic Tafel slope

Table 3 - Passivity Characteristics Obtained from Potentiodynamic Polarization Scans of Dissimilar RSW Joints (FZ) and Austenitic Stainless Steel Base Material (BM) in $0.5 \mathrm{M} \mathrm{H}_{2} \mathrm{SO}_{4}$ Containing Naturally Dissolved $\mathrm{O}_{2}$ at $25^{\circ} \mathrm{C}$

\begin{tabular}{cccccc} 
& $E_{p p}(V)$ & $i_{c r t}\left(m A / \mathrm{cm}^{2}\right)$ & $E_{c p}(V)$ & $i_{\text {pass }}\left(\mathrm{mA}^{2} / \mathrm{cm}^{2}\right)$ & $0.002 \pm 0.001$ \\
\hline BM & $-0.150 \pm 0.02$ & $0.019 \pm 0.01$ & $-0.01 \pm 0.05$ & $0.004 \pm 0.001$ & $1.00 \pm 0.00$ \\
FZ & $-0.130 \pm 0.04$ & $0.033 \pm 0.02$ & $0.219 \pm 0.06$ & 0.004 \\
\hline
\end{tabular}

$E_{p p}-$ potential for primary passivation; $i_{c r t}-$ critical current density for passivation; $E_{c p}-$ potential for complete passivation; $i_{\text {pass }}-$ passive current density; $E_{t p}-$ transpassive potential 


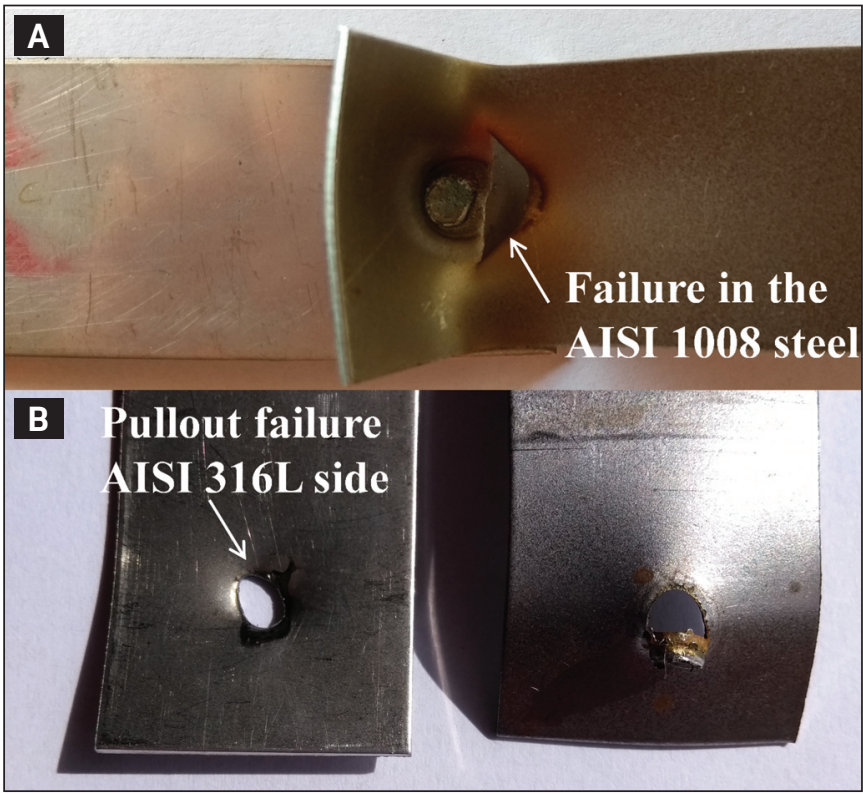

Fig. 7-Comparison of failure mechanisms of the dissimilar welded joints before and after hydrogen charging at 100 $\mathrm{mA} / \mathrm{cm}^{2}$.

along which Vickers microhardness measurements were performed - Fig. 3. The welding parameters employed led to complete penetration of the sheets on both sides of the joints. The microstructures of the carbon steel HAZ and of the FZ are highlighted in Fig. 2B and C, respectively.

The results presented in Fig. 3 indicate moderate hardening in the carbon steel HAZ, which exhibited a partially martensitic microstructure as shown in Fig. 2B. In addition, elevated hardness values were noticed in the FZ (480 $\mathrm{HV}$ on average), with slightly higher hardness values closer to the carbon steel side of the joint (503 HV) that decreased along line DD' (Fig. 1) toward the stainless steel side $(457 \mathrm{HV})$. Both the elevated hardness values and the decreasing trend approaching the stainless steel base material are consistent with a martensitic (or predominantly martensitic) microstructure in the FZ, since the hardness of martensite is strongly influenced by carbon content expected to be higher close to the AISI 1008 steel side. This is in agreement with theoretical predictions using Schaeffler's diagram, considering the $\mathrm{Cr}_{\mathrm{eq}}$ and $\mathrm{Ni}_{\text {eq }}$ values presented in Table 1 and a dilution of $40 \%$ (carbon steel to stainless steel ratio in the FZ), which was estimated based on the EDS values identified in Fig. 1A. The presence of martensite in the FZ of dissimilar carbon and stainless steel RSW joints is expected because of the accelerated cooling rates observed after the process, as previously reported in the literature (Refs. 4, 5, 25-27).

\section{Electrochemical Corrosion Behavior}

The welding parameters employed caused the FZ microstructure to be present on the stainless steel side of the welded joint, which allowed for an examination of the corrosion behavior of the weld nugget. The results of the potentiodynamic polarization scans performed at room temperature are presented in Fig. 4 for the stainless steel base material (BM) and the dissimilar weld. The main parameters that can be extracted from the polarization curves presented in Fig. 4 are summarized in Tables 2 and 3.

Regarding uniform corrosion behavior (Table 2), it is possible to notice that the weld exhibited slightly more chemically active behavior, with the corrosion potential shifting towards more anodic (negative) values. This result is consistent with the presence of martensite in the FZ, which is more reactive compared to the austenitic structure of the stainless steel BM. Regarding the actual corrosion rate expressed in terms of $i_{\text {corr }}$, however, the values obtained did not present statistically relevant differences given the error ranges obtained (Table 2 ). It is worth noticing that the cathodic Tafel slopes $\left(b_{c}\right)$ are compatible with the theoretical value of $-0.120 \mathrm{~V} / \mathrm{dec}$, indicating that the cathodic reaction proceeds with a single electron transfer step for the hydrogen evolution reaction (Refs. 28): $\mathrm{H}_{\mathrm{ads}}+\mathrm{H}^{+}+\mathrm{e}^{-} \rightarrow \mathrm{H}_{2}$. It is worth noticing that while the same mechanism for the cathodic reaction can be attributed to both sample groups, it is clear from the results presented in Fig. 4 that the cathodic reaction rate observed in the weld is significantly higher in comparison to the BM, suggesting a more reactive surface in spite of the similar $i_{\text {corr }}$ values registered in Table 2 .

Since stainless steels are passivated in acid media, it is important to also consider the passivity characteristics of the materials to correctly assess their corrosion behavior. By analyzing the results presented in Fig. 4, it is possible to notice that both materials exhibited an active-passive behavior with different passivity ranges, i.e., the difference between the potential for complete passivation $\left(\mathrm{E}_{\mathrm{cp}}\right)$ and the transpassive potential $\left(\mathrm{E}_{\mathrm{tp}}\right)$, presented in Table 3 . The critical current density $\left(i_{\text {crt }}\right)$ was also higher for the welded sample, which indicates a larger amount of dissolution took place before the formation of the passive film on the metal surface. However, once the passive film was established, its protective properties seemed equivalent for the weld and BM samples, since the passive current density ( $i_{\text {pass }}$, determined as the average along the entire passivity range) did not alter significantly. Hence, the results indicate passive film formation on the dissimilar welded joint

Table 4 - ElS Parameters Obtained for the Dissimilar RSW Joints (FZ) and Austenitic Stainless Steel Base Material (BM) in $0.5 \mathrm{M} \mathrm{H}_{2} \mathrm{SO}_{4}$ Containing Naturally Dissolved $\mathrm{O}_{2}$ at OCP

\begin{tabular}{cccc} 
& $\mathrm{R}_{\mathrm{s}}\left(\Omega \mathrm{cm}^{2}\right)$ & $\mathrm{R}_{\mathrm{p}}\left(\Omega \mathrm{cm}^{2}\right)$ & $\mathrm{R}_{\mathrm{cp}}\left(\Omega \mathrm{cm} \mathrm{cm}^{2}\right)$ \\
\hline BM & 4.16 & 264.0 & 1220 \\
FZ & 7.95 & 41.6 & 66.0 \\
\hline
\end{tabular}

$\mathrm{R}_{\mathrm{s}}$ - solution impedance; $\mathrm{R}_{\mathrm{p}}$ - polarization resistance of the metal/electrolyte interface; $\mathrm{R}_{\mathrm{cp}}$ - polarization resistance of the oxide/electrolyte interface 
required a larger amount of metal consumption, most probably a consequence of dilution in the FZ and lower amounts of available $\mathrm{Cr}$ and/or Ni. However, once developed, the passive films had practically the same effect on limiting dissolution rates.

The results of the EIS measurements are presented in Fig. 5 in the form of Bode diagrams along with the equivalent circuit model used for extracting the electrochemical parameters, which are presented in Table 4 . The model presented in Fig. 5 takes into account the presence of an oxide film on the metal surface that is partially permeated by the electrolyte (either by the presence of cracks or pores or simply because of incomplete surface coverage). Thus, the whole ensemble is formed of the polarization resistance $\left(R_{p}\right)$, oxide film resistance $\left(R_{c p}\right)$, and solution resistance $\left(R_{s}\right)$. The reason for using such a model relies on the fact two time constants were apparent in the experimental data (as revealed by the inflection point at the level of $R_{c p}+R_{s}$ in Fig. 5) and also because after 1.5 -h exposure to the acid solution (for OCP stabilization, the condition at which the EIS data was collected), the presence of oxides could be verified on the sample surfaces. Even though the results obtained from the polarization diagrams (Table 2) were not conclusive concerning the corrosion rate $\left(i_{\text {corr }}\right)$, the EIS data did reveal a difference in polarization resistance $\left(R_{p}\right)$, which is inversely proportional to the corrosion current density. The $R_{p}$ values obtained revealed a decrease in uniform corrosion resistance of the weld in comparison to the BM. In addition, it was found the impedance due to the presence of the oxide film $\left(R_{c p}\right)$ at the OCP for the welded sample was significantly lower compared to the nonwelded stainless steel specimen (Table 4). Thus, the freely corroding surface of the welded joint was less effectively protected compared to the original stainless steel base material.

\section{Hydrogen Embrittlement}

The susceptibility to hydrogen embrittlement of the dissimilar welded joints was analyzed by applying tensile-shear tests before and after cathodic charging at $100 \mathrm{~mA} / \mathrm{cm}^{2}$, and the results are presented in Fig. 6. It is possible to notice that after hydrogen permeation, both peak load $\left(\mathrm{F}_{\max }\right)$ and maximum elongation $\left(\Delta \mathrm{l}_{\max }\right)$ were reduced. The relative loss in $\Delta \mathrm{l}_{\max }$ (from $6.60 \pm 0.8 \mathrm{~mm}$ to $4.90 \pm 0.05$ ) was used to compute the hydrogen embrittlement index, and the value obtained was $42 \pm 5 \%$ (standard deviation of three tested samples), which indicates the welded region is sensitive to the presence of hydrogen, a consequence of its predominantly martensitic microstructure. With regard to the failure mechanism, it is worth observing that prior to hydrogen permeation, the dissimilar welded joint failed by nugget pullout followed by tearing of the AISI 1008 carbon steel sheet. After hydrogen charging, failure still occurred by pullout, but a complete withdrawal of the weld nugget was observed from the stainless steel side of the joint instead (the side exposed to hydrogen charging), as shown in Fig. 7.

It is important to notice that both the sensitivity to hydrogen and the reduction in corrosion resistance noticed in the previous section are related to the exposure of the martensitic FZ microstructure to the acid environments in which these results were obtained. This, in turn, is a conse- quence of the complete penetration of the welded joints. Thus, the results presented here indicate that if the electrochemical behavior of the base material is to be preserved, the nugget size of the dissimilar weld should be controlled to avoid formation of the typical FZ microstructure on the surface of the welded joints.

\section{Conclusions}

In the present work, dissimilar joints of low-carbon steel and austenitic stainless steel were produced by RSW and evaluated in terms of mechanical properties, microstructure, and electrochemical behavior. The dissimilar welds exhibited a positive relation between welding current and peak load in tensile-shear tests below the maximum welding current of $13.8 \mathrm{kA}$, and elevated hardness in the $\mathrm{FZ}(\sim 480 \mathrm{HV})$. The presence of martensite in the FZ of the welded joints, along with the reduction in the amounts of alloying elements such as $\mathrm{Cr}$ and $\mathrm{Ni}$, were connected with a reduction in corrosion resistance, both in terms of uniform corrosion and passivity behavior. Finally, the FZ of the dissimilar welded joints were found to be susceptible to hydrogen embrittlement, leading to a significant loss ductility.

\section{Acknowledgments}

The authors are grateful to technical staff at the Pontifical Catholic University of Minas Gerais for assistance during welding experiments.

\section{References}

1. Pouranvari, M., and Marashi, S. P. H. 2013. Critical review of automotive steels spot welding: Process, structure and properties. Science and Technology of Welding and Joining 18(5): 361-403. DOI: 10.1179/1362171813Y.0000000120

2. Varavallo, R., Melo Moreira, V., Paes, V., Brito, P., Olivas, J., and Pinto, H. C. 2014. Welding induced residual stresses in explosion cladded AL-6XN superaustenitc stainless steel and ASME SA516-70 steel composite plates. Advanced Materials Research 996: 451-456. DOI: 10.4028/ www.scientific.net/AMR.996.451

3. Coelho, R. S., Kostka, A., Sheikhi, S., Dos Santos, J. F., and Pyzalla, A. R. 2008. Microstructure and mechanical properties of an AA6181-T4 aluminium alloy to HC340LA high strength steel friction stir overlap weld. Advanced Engineering Materials 10(10): 961-972. DOI: 10.1002/adem.200800028

4. Marashi, P., Pouranvari, M., Amirabdollahian, S., Abedi, A., and Goodarzi, M. 2008. Microstructure and failure behavior of dissimilar resistance spot welds between low carbon galvanized and austenitic stainless steels. Materials Science and Engineering A 480(1-2): 175-180. DOI: 10.1016/j.msea.2007.07.007

5. Pouranvari, M., and Marashi, S. P. H. 2009. Similar and dissimilar RSW of low carbon and austenitic stainless steels: Effect of weld microstructure and hardness profile on failure mode. Materials Science and Technology 25(12): 1411-1416. DOI: 10.1179/ 026708309X12459430509292

6. Aravinthan, A., and Nachimani, C. 2011. Analysis of spot weld growth on mild and stainless steel. Welding Journal 90(8): 
143 -s to 147 -s.

7. Kolařík, L., Sahul, M., Kolaříková, Sahul, M., Turňa, M., and Felix, M. 2012. Resistance spot welding of dissimilar steels. Acta Polytechnica 52(3): 43-47.

8. Jamasri, M. N., Ilman, R., and Soekrisno, T. 2011. Corrosion fatigue behavior of resistance spot welded dissimilar metal welds between carbon steel and austenitic stainless steel with different thickness. Procedia Engineering 10: 649-654. DOI: 10.1016/j. proeng.2011.04.108

9. Pouranvari, M., Khorramifar, M., and Marashi, S. P. H. 2016. Ferritic-austenitic stainless steels dissimilar resistance spot welds: Metallurgical and failure characteristics. Science and Technology of Welding and Joining 21(6): 438-445. DOI: 10.1080/13621718. 2015.1124491

10. Pouranvari, M., Alizadeh-Sh, M., and Marashi, S. P. H. 2015. Welding metallurgy of stainless steels during resistance spot welding Part I: Fusion zone. Science and Technology of Welding and Joining 20(6): 502-511. DOI: 10.1179/1362171815Y.0000000015

11. Alizadeh-Sh, M., Pouranvari, M., and Marashi., S. P. H. 2015. Welding metallurgy of stainless steels during resistance spot welding Part II - Heat affected zone and mechanical performance. Science and Technology of Welding and Joining 20(6): 512-521. DOI: 10.1179/1362171815Y. 0000000010

12. Alenius, M., Pohjanne, P., Somervuori, M., and Hanninen, H. 2006. Exploring the mechanical properties of spot welded dissimilar joints for stainless and galvanized steels. Welding Journal 85(12): 305-s to 313-s.

13. Martín, Ó., De Tiedra, P., and López, M. 2010. Artificial neural networks for pitting potential prediction of resistance spot welding joints of AISI 304 austenitic stainless steel. Corrosion Science 52(7): 2397-2402. DOI: 10.1016/j.corsci.2010.03.013

14. De Tiedra, P., Martín, Ó., and López, M. 2011. Combined effect of resistance spot welding and post-welding sensitization on the degree of sensitization of AISI 304 stainless steel. Corrosion Science 53(8): 2670-2675. DOI: 10.1016/j.corsci.2011.05.007

15. De Tiedra, P., Martín, Ó., López, M., and San-Juan, M. 2011. Use of EPR test to study the degree of sensitization in resistance spot welding joints of AISI 304 austenitic stainless steel. Corrosion Science 53(4): 1563-1570. DOI: 10.1016/j.corsci.2011.01.036

16. Nanninga, N., Grochowsi, J., Heldt, L., and Rundman, K. 2010. Role of microstructure, composition and hardness in resisting hydrogen embrittlement of fastener grade steels. Corrosion Science 52(4): 1237-1246. DOI: 10.1016/j.corsci.2009.12.020

17. Li, X., Gong, B., Deng, C., and Li, Y. 2018. Failure mechanism transition of hydrogen embrittlement in AISI 304 K-TIG weld metal under tensile loading. Corrosion Science 130: 241-251. DOI: 10.1016/j.corsci.2017.10.032

18. Li, X., Gong, B., Deng, C., and Li, Y. 2019. Effect of prestrain on microstructure and hydrogen embrittlement of K-TIG welded austenitic stainless steel. Corrosion Science 149(1): 1-17. DOI: 10.1016/j.corsci.2018.12.018

19. Hanninen, H., and Hakarainen, T. 1980. On the effects of $\alpha^{\prime}$ martensite in hydrogen embrittlement of a cathodically charged AISI type 304 austenitic stainless steel. Corrosion 36(1): 47-51. DOI: 10.5006/0010-9312-36.1.47

20. Depover, T., Pérez Escobar, D., Wallaert, E., Zermout, Z., and Verbeken, K. 2014. Effect of hydrogen charging on the mechanical properties of advanced high strength steels. International Journal of Hydrogen Energy 39(9): 4647-4656. DOI: 10.1016/j.ijhydene.2013.12.190

21. Troselius, L. 1971. Polarization performance of stainless steels in $\mathrm{H}_{2} \mathrm{SO}_{4}$ and $\mathrm{HCl}$. Corrosion Science 11(7): 473-484. DOI: 10.1016/S0010-938X(71)80015-X

22. Chao, Y. J. 2003. Failure mode of spot welds: Interfacial versus pullout. Science and Technology of Welding and Joining 8(2): 62-68.

23. Pouranvari, M. G. M., and Marashi, P. 2008. Failure mode of dissimilar resistance spot welds between austenitic stainless and low carbon steels. Metals 13: 1-6.

24. Pouranvari, M., Marashi, S. P. H., and Mousavizadeh, S. M. 2010. Failure mode transition and mechanical properties of similar and dissimilar resistance spot welds of DP600 and low carbon steels. Science and Technology of Welding and Joining 15: 625-631. DOI: 10.1179/136217110X12813393169534

25. Marashi, P., Pouranvari, M., Sanaee, S. M. H., Abedi, A., Abootalebi, S. H., and Goodarzi, M. Relationship between failure behaviour and weld fusion zone attributes of austenitic stainless steel resistance spot welds. Materials Science and Technology 24: 1506-1512. DOI: 10.1179/174328408X262418

26. Kianersi, D., Mostafaei, A., and Amadeh, A. A. 2014. Resistance spot welding joints of AISI 316L austenitic stainless steel sheets: Phase transformations, mechanical properties and microstructure characterizations. Materials and Design 61: 251-263. DOI: 10.1016/j.matdes.2014.04.075

27. Abadi, M., and Pouranvari, M. M. H. 2010. Correlation between macro/micro structure and mechanical properties of dissimilar resistance spot welds of AISI 304 austenitic stainless steel and AISI 1008 low carbon steel. Association of Metallurgical Engineers of Serbia 16(2): 133-146.

28. McCafferty, E. 2010. Introduction to Corrosion Science. p. 583, New York, N. Y.: Springer.

DIEGO FONSECA SILVA and PEDRO PAIVA BRITO (pbrito@ pucminas.br) are with the Department of Mechanical Engineering, Pontifical Catholic University of Minas Gerais, Belo Horizonte, Brazil.

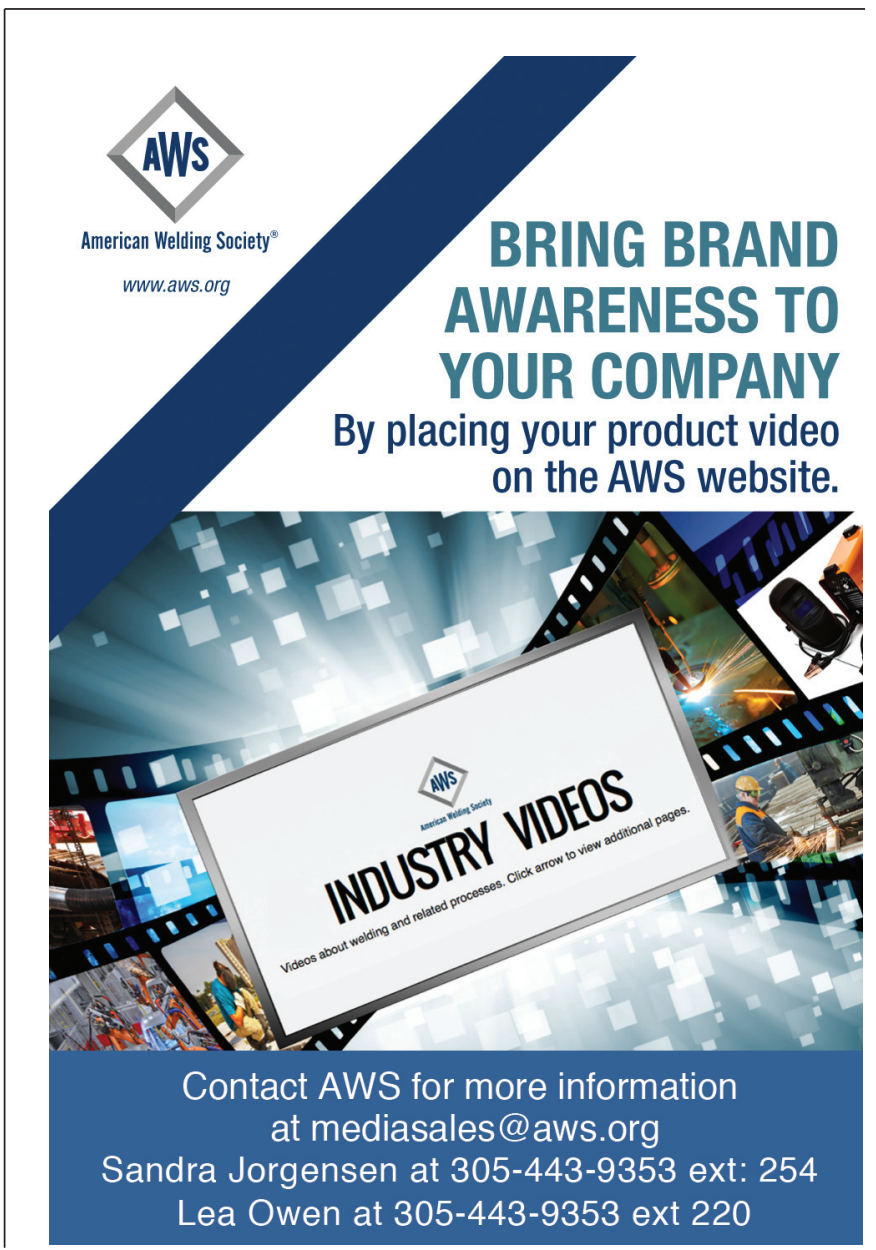

